\title{
BIAN N-Heterocyclic Gold Carbene Complexes induced cytotoxicity in human cancer cells via upregulating oxidative stress
}

\author{
Muhammad Farooq ${ }^{1 *}$, Nael Abu Taha ${ }^{1}$, Rachel R Butorac ${ }^{2}$, Daniel A Evans ${ }^{2}$, \\ Ahmed A Elzatahry ${ }^{3}$, Mohammad AM Wadaan', Alan H Cowley ${ }^{2}$
}

\begin{abstract}
Background: Nanoparticles of gold and silver are offering revolutionary changes in the field of cancer therapy. $\mathrm{N}$-heterocyclic carbene (NHC) metal complexes possess diverse biological activities and are being investigated as potential chemotherapeutic agents. The purpose of this study was to examine the cytotoxicity and possible mechanisms of action of two types of newly synthesized nanofiber composites containing BIAN N-heterocyclic gold carbene complexes in two types of human cancer cells, namely breast cancer (MCF7) and liver cancer (HepG2) cells and also in normal human embryonic kidney cells (HEK 293). Materials and Methods: Cytotoxicity was assessed by MTT cell viability assay and oxidative stress by checking the total glutathione level. Both compounds affected the cell survival of the tested cell lines at very low concentrations (IC50 values in the micro molar range) as compared to a well-known anti-cancer drug, 5 fluorouracil. A 60-80\% depletion in total glutathione level was detected in treated cells. Conclusions: Reduction in total glutathione level is one of the biochemical pathways for the induction of oxidative stress which in turn could be a possible mechanism of action by which these compounds induce cytotoxicity in cancer cell lines. The in vitro toxicity towards cancer cells found here means that these molecules could be potential anticancer candidates.
\end{abstract}

Keywords: BIAN N-heterocyclic carbene complexes - nanofiber composite - cytotoxicity - oxidative stress

Asian Pac J Cancer Prev, 16 (16), 7003-7006

\section{Introduction}

A carbene is a divalent carbon atom linked to two other groups by covalent bonds, and possesses two unshared valence electrons. These electrons can be paired in the same orbital as anti-parallel spins (singlet) represented as $\sigma 2$ or $p \pi 2$ in different orbitals, or as parallel spins (triplet) represented as $\sigma 1 \mathrm{p} \pi 1$. (Droge and Glorius, 2010). $\mathrm{N}-\mathrm{Heterocyclic}$ carbenes (NHCs) are singlet carbenes in which the $\mathrm{E}$ substituents are nitrogen atoms; these carbenes are neutral 2-electron donors, with an ability to bond to both hard and soft metals, making them versatile ligands (Weskamp et al., 1999; Herrmann, 2002).

NHCs are easy to synthesize and functionalize since they form a stronger bond to metals and therefore form more stable metal complexes. The reactivity of a carbene is influenced by the nature of the substituents attached to the carbene carbon atom (Bourissou et al., 2000). The N-heterocyclic carbene (NHC) metal complexes possess diverse biological activities and a few of them have been reported as potential chemotherapeutic agents (Hindi et al., 2009; Teyssot et al., 2009; Gautier and
Cisnetti, 2012; Liu and Gust, 2013b) So far very few gold- N-heterocyclic carbene metal complexes have been synthesized. The cationic Au (I) complexes of NHCs and 1,3-diethylbenzimidazol-2-ylidene N-heterocyclic carbene (NHC) ligands of the type NHC-Au-L (where $\mathrm{L}=-\mathrm{Cl},-\mathrm{NHC}$, or $-\mathrm{PPh} 3$ ) have been reported to have dual properties in a single molecule by targeting the mitochondria of cancer cells and by selective inhibition of thioredoxin reductase (Hickey et al., 2008a; Rubbiani et al., 2011). The anti-mitochondrial properties of cationic, linear $\mathrm{Au}(\mathrm{I}) \mathrm{N}$-heterocyclic carbene complexes have also been reported in another study (Baker et al., 2006).

Even though the gold N-heterocyclic carbene complexes have been shown to have great commercial value for medical applications, there is often a lack of relevant safety and toxicology data. Recently, nanoparticles have been emerging as promising agents for cancer therapy and are being investigated as contrast agents, drug carriers, radiosensitizers (Islamian et al., 2015). Daduang et al., (Daduang et al., 2015) proposed that gold nanoparticles have the potential to be used as phytochemical delivery agents for alternative cancer

${ }^{1}$ Bioproducts Research Chair, Department of Zoology, College of Science, King Saud University, Riyadh, Kingdom of Saudi Arabia, ${ }^{2}$ Department of Chemistry, The University of Texas at Austin, Austin, TX, USA, ${ }^{3}$ Materials Science and Technology Program, College of Arts and Sciences, Qatar University, Doha, Qatar*For correspondence: fmuhammad@ksu.edu.sa 
treatment to reduce the side effects of radiotherapy and chemotherapy. In another study (Selim and Hendi, 2012) the gold nanoparticles have been shown to upregulate the mRNA expression of p53, bax, caspase- 3 \& caspase-9, whereas expression of antiapoptotic bcl-2 was downregulated in human breast epithelial MCF-7 cells.

We have previously reported the synthesis of nanofiber composite bis(imino)acenaphthene (BIAN) NHC gold carbene complexes and their antimicrobial and antifungal activities (Butorac et al., 2011; Elzatahry et al., 2012). The objective of this study was to test the cytotoxicity of these newly synthesized BIAN N-heterocyclic gold carbene complexes in vitro in two types of human cancer cells, namely, breast cancer (MCF7) and liver cancer (HepG2) cells. The cytotoxicity was also tested in normal human cells (human embryonic kidney cells HEK 293) to evaluate whether they are toxic to all cells or induce toxicity only in cancer cells. For this purpose a human cell line which is derived from normal was used.

\section{Materials and Methods}

\section{Synthesis of BIAN NHC gold complexes}

The BIAN NHC gold complexes [IPr(BIAN)AuCl] and [IPr(BIAN)AuOAc] were synthesized as reported previously (Vasudevan et al., 2010; Butorac et al., 2011)

\section{Cell culture and cell viability assay}

The HepG2, MCF7 and HEK293 cells were obtained from ATCC and cultured following standard cell culture procedures. Briefly, $\sim 5 \times 103$ cells were seeded in each well of a 12-well cell culture plate in high glucose Dulbecco's Modified Eagle Medium (DMEM: Life technologies cat \# 11995073) supplemented with 10\% Fetal bovine serum (FBS: Life technologies cat \# 16000044) in a humidified incubator with $5 \% \mathrm{CO} 2$ at $37^{\circ} \mathrm{C}$ for 24 hours The various indicated concentrations of the compounds were added to wells in triplicate and the cells were cultured with these compounds for further 24 hours. Cell viability was determined using a MTT cell viability assay as described previously (Farooq et al., 2014)

\section{Measurement of glutathione (GSH) level in cancer cells}

The changes in the GSH levels in the exposed cells were determined using a commercially available kit (Glutathione Assay Kit, Catalogue Number CS0260; Sigma- Aldrich 3050 Spruce Street, St Louis Mo 63103 USA). In order to check the total glutathione level in the cells, the cells were exposed to the gold carbene NHC complexes for 24 hours. Following exposure, cells (both treated and control) were rinsed three times in PBS. The cells were then homogenized in a cold assay buffer (100 mM potassium phosphate buffer, $\mathrm{pH} 7.0$, with 1 mM EDTA). The resulting homogenate was centrifuged at $10,000 \mathrm{rpm}$ for $15 \mathrm{~min}$ at $4{ }^{\circ} \mathrm{C}$, and the supernatant was collected and deprotonated by treatment with $5 \%$ 5- Sulphosalicylic Acid. The total glutathione level was then measured by reading the samples in a plate reader.

-All data are expressed as mean \pm S.D, using the values obtained from three independent experiments. Statistical analysis was performed by one-way analysis of variance (ANOVA) using Origin v6.1052 (Origin Lab Corporation, Northampton MA USA). Unless stated otherwise, the chosen level of statistical significance was $\mathrm{p}<0.05$.

\section{Results}

Testing in vitro toxicity of BIAN N-Heterocyclic gold carbene in human cancer cells

The chemical structure and synthesis scheme of the newly synthesized nanofiber composite BIAN $\mathrm{N}$-Heterocyclic gold carbene complexes is given in Figure 1. In order to evaluate the in vitro cytotoxicity or anti-cancer profile of these two compounds, two types of human cancer cells, namely liver carcinoma (HepG2) and breast carcinoma (MCF7), were tested, along with one type of normal cells i.e. human embryonic kidney cells (HEK293). A pronounced activity (IC50 values in the very low micro molar range) was observed for both of the gold carbene complexes in the tumour cell lines. The gold acetate complex [IPr(BIAN)AuOAc] turned out to be more cytotoxic than the corresponding gold chloride complex [IPr(BIAN)AuCl]. As presented in Table 1, the IC50 values for the gold acetate compounds were 0.971 \pm 0.100 and $0.455 \pm 0.016 \mu \mathrm{M}$ for breast cancer and liver cancer cells, respectively. On the other hand, the IC50 values exceeded $1 \mu \mathrm{M}$ in the case of the gold chloride complex for both cell types (Table 1). The cytotoxicity of BIAN N-Heterocyclic gold carbine complexes was also much higher than the reference compound 5-flourouracil (5FU). The IC50 values for 5-FU were $32.1572 \pm 2.168$ and $35.456 \pm 2.98 \mu \mathrm{M}$ in breast cancer and liver cancer cells, respectively, which is much higher than either of the BIAN N-Heterocyclic gold carbene complexes.

The BIAN N-Heterocyclic gold carbene complexes also turned out to be highly selective in exerting their toxicity in cancer cells. When tested in normal embryonic kidney cells, the IC50 values were much higher than for cancer cells. The gold acetate complex was again more toxic than gold chloride complex, with IC50 values in HEK 293 cells of $9.34 \pm 1.033 \mu \mathrm{M}$ compared to 32.544 $\pm 0.051 \mu \mathrm{M}$ for the gold chloride compound.

The nanofiber composite containing IBAN Nheterocyclic gold complexes induced cytotoxicity via elevating the oxidative stress

Most of nanoparticles have been reported to exert cytotoxicity and apoptosis via raising the oxidative stress in exposed cells. The final phase of the work is based on the question of whether the cytotoxicity observed with the $\mathrm{N}$-heterocyclic gold carbene complexes in human cells line is also due to the introduction of oxidative stress. In order to check the ROS levels in the treated cells, the total glutathione levels were measured by means of spectrophotometric assays. A depletion of glutathione was detected in the MCF7 and HepG2 cells for both of these compounds. As might be anticipated, the gold acetate complex was found to be more potent than the corresponding gold chloride complex in terms of the induction of oxidative stress. The gold acetate carbene complex reduced almost $70 \%$ of the glutathione level in MCF7 and HepG2 cells, while a $62 \%$ depletion in the 
Nanofiber Composites Containing BIAN N-heterocyclic Gold Carbene Complexes and Cytotoxicity in Human Cancer Cells Table 1. Cell Survival Effects for MCF-7, HepG2 and HEK 293 Cells

\begin{tabular}{lccc}
\hline Compound ID & IC50 MCF7 $(\mu \mathrm{M})$ & IC50 HepG2 $(\mu \mathrm{M})$ & IC50 HEK $293(\mu \mathrm{M})$ \\
\hline IIPr(BIAN)AuOAc] & $* * 0.971 \pm 0.100$ & $* * 0.455 \pm 0.016$ & $* 9.34 \pm 1.033$ \\
[IPr(BIAN)AuCl] & $* 1.036 \pm 0.125$ & $* 2.89 \pm 0.033$ & I $32.544 \pm 0.051$ \\
5-FU & $* 32.1572 \pm 2.168$ & $* 35.456 \pm 2.98$ & I $51.1668 \pm 102.9$ \\
\hline
\end{tabular}

The results are expressed as IC50 values based on the mean values ( \pm St Dev) of triplicate experiments; $*$ p $<0.05$ compared to control (mock treated); ** $\mathrm{p}<0.005$ compared to control (mock treated; I Statically not significant as compared to control

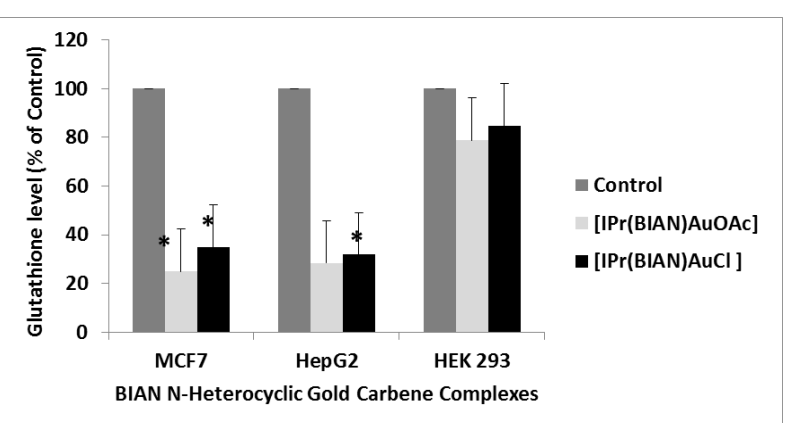

Figure 1. Glutathione (GSH) Levels in Human Cell Lines Exposed for $24 \mathrm{~h}$ to Each Compound at $0.5 \mu \mathrm{M}$. Each Histogram Represents the mean \pm SD of three Independent Experiments. $* P<0.05$ vs control (mock treated cells)

glutathione level was observed in the case of the gold chloride complex (Figure 1). A depletion of glutathione was also evident in the HEK 293 cells, but this was insignificant compared with the values that were observed for the MCF7 and HepG2 cells. These results indicate that elevating of oxidative stress via depleting the glutathione in exposed cells could be one of possible mechanism by which the gold carbene complexes induced cell death in cancer cells in this study.

\section{Discussion}

Several anticancer drugs have significant limitations such as neurotoxicity, nephrotoxicity, and the development of resistance in some cancer cells (Berners-Price, 2011; Nardon et al., 2014). In order to overcome these limitations, a variety of different metal containing complexes are currently being studied as potential anticancer agents. Among such compounds, the metal $\mathrm{N}$-heterocyclic carbene (NHC) complexes are beginning to attract significant attention on account of their efficient drug design (Liu and Gust, 2013a) Of the various metal NHC complexes that have been prepared thus far, the silver and gold NHC complexes show considerable promise as anti-microbial and anticancer agents (Melaiye et al., 2004; Hickey et al., 2008b; Ozdemir et al., 2010; Elzatahry et al., 2012).

At the present time, while there is no publication that addresses the biological activities of BIAN N-heterocyclic gold carbene complexes in cancer cells, the antiproliferative activities of ruthenium (II) N-heterocyclic carbene complexes have been reported for MCF7 and HT-29 cells, with IC50 values ranging from 2- $50 \mu \mathrm{M}$. (Oehninger et al., 2013). Overall, the compounds that are reported in the present work are particularly active in terms of inducing cytotoxicity at very low IC50 values in vitro for both human cancer cell lines. Recent studies have revealed that changes in the intracellular surroundings of the cells, such as alterations to the redox environment, serve as important regulators for the progression to apoptosis (Pervaiz and Clement, 2002; Franco and Cidlowski, 2009). The induction of reactive oxygen species (ROS) is a common mechanism of cell death by nanoparticles in exposed cells. (Alfaro et al., 2010; Tedesco et al., 2010; Manke et al., 2013; Oehninger et al., 2013; Mateo et al., 2014). In agreement with these studies we also have found a significant elevation of oxidative stress in exposed human cancer cell line (HepG2 and MCF7) and elevation of oxidative stress could possibly be the one of mechanism through which these compounds induced cytotoxicity in cancer cell lines.

In conclusion, Overall the cytotoxicity profile of novel BIAN N-Heterocyclic gold carbene complexes in three human cell line has been reported. The cell viability data in human cells has shown that cancer cells (breast cancer and liver cancer) were more vulnerable to cell death compared to normal cells under the exposure of BIAN N-Heterocyclic gold carbene complexes and hence warrants further investigation to find out the molecular targets in cancer cells in order to evaluate the pharmaceutical application of these compounds as anticancer drugs.

\section{Acknowledgements}

The authors extend their sincere appreciation to the Deanship of Scientific Research at King Saud University (Research Project RGO-VPP-284) for funding this work. We also thanks to the Robert A. Welch Foundation (Grant F-0003)

\section{References}

Alfaro JM, Prades A, del Carmen Ramos M, et al (2010). Biomedical properties of a series of ruthenium-Nheterocyclic carbene complexes based on oxidant activity in vitro and assessment in vivo of biosafety in zebrafish embryos. Zebrafish, 7, 13-21.

Baker MV, Barnard PJ, Berners-Price SJ, et al (2006). Cationic, linear $\mathrm{Au}(\mathrm{i}) \mathrm{N}$-heterocyclic carbene complexes: synthesis, structure and anti-mitochondrial activity. Dalton Transactions, 3708-15.

Berners-Price SJ (2011). Activating platinum anticancer complexes with visible light. Angew Chem Int Ed Engl, 50, 804-5.

Bourissou D, Guerret O, Gabbai FP, et al (2000). Stable Carbenes. Chemical Reviews, 100, 39-92.

Butorac RR, Al-Deyab SS, Cowley AH (2011). Antimicrobial properties of some bis(iminoacenaphthene (BIAN)supported $\mathrm{N}$-heterocyclic carbene complexes of silver and 
Muhammad Farooq et al gold. Molecules, 16, 2285-92.

Daduang J, Palasap A, Daduang S, et al (2015). Gallic acid enhancement of gold nanoparticle anticancer activity in cervical cancer cells. Asian Pac J Cancer Prev, 16, 169-74.

Droge T, Glorius F (2010). The measure of all rings-nheterocyclic carbenes. Angewandte Chemie-International Edition, 49, 6940-52.

Elzatahry AA, Al-Enizi AM, Elsayed EA, et al (2012). Nanofiber composites containing $\mathrm{N}$-heterocyclic carbene complexes with antimicrobial activity. Int J Nanomedicine, 7, 2829-32.

Farooq M, El-Faham A, Khattab SN, et al (2014). Biological screening of novel derivatives of valproic acid for anticancer and antiangiogenic properties. Asian Pac J Cancer Prev, 15, 7785-92.

Franco R, Cidlowski JA (2009). Apoptosis and glutathione: beyond an antioxidant. Cell Death Differ, 16, 1303-14.

Gautier A, Cisnetti F (2012). Advances in metal-carbene complexes as potent anti-cancer agents. Metallomics, $\mathbf{4}$, 23-32.

Herrmann WA (2002). N-heterocyclic carbenes: a new concept in organometallic catalysis. Angew Chem Int Ed Engl, 41, 1290-309.

Hickey JL, Ruhayel RA, Barnard PJ, et al (2008a). Mitochondriatargeted chemotherapeutics: the rational design of gold(I) $\mathrm{N}$-heterocyclic carbene complexes that are selectively toxic to cancer cells and target protein selenols in preference to thiols. J Am Chem Soc, 130, 12570-1.

Hickey JL, Ruhayel RA, Barnard PJ, et al (2008b). Mitochondriatargeted chemotherapeutics: the rational design of gold(I) $\mathrm{N}$-heterocyclic carbene complexes that are selectively toxic to cancer cells and target protein selenols in preference to thiols. J Am Chem Soc, 130, 12570-1.

Hindi KM, Panzner MJ, Tessier CA, et al (2009). The medicinal applications of imidazolium carbene-metal complexes. Chemical Reviews, 109, 3859-84.

Islamian JP, Hatamian M, Rashidi MR (2015). Nanoparticles promise new methods to boost oncology outcomes in breast cancer. Asian Pac J Cancer Prev, 16, 1683-6.

Liu W, Gust R (2013a). Metal N-heterocyclic carbene complexes as potential antitumor metallodrugs. Chem Soc Rev, 42, 755-73.

Liu WK, Gust R (2013b). Metal N-heterocyclic carbene complexes as potential antitumor metallodrugs. Chem Soc Rev, 42, 755-73.

Manke A, Wang LY, Rojanasakul Y (2013). Mechanisms of nanoparticle-induced oxidative stress and toxicity. biomed research international.

Mateo D, Morales P, Avalos A, et al (2014). Oxidative stress contributes to gold nanoparticle-induced cytotoxicity in human tumor cells. Toxicology Mechanisms and Methods, 24, 161-72.

Melaiye A, Simons RS, Milsted A, et al (2004). Formation of water-soluble pincer silver(I)-carbene complexes: a novel antimicrobial agent. J Med Chem, 47, 973-7.

Nardon C, Boscutti G, Fregona D (2014). Beyond platinums: gold complexes as anticancer agents. Anticancer Res, 34, 487-92.

Oehninger L, Stefanopoulou M, Alborzinia H, et al (2013). Evaluation of arene ruthenium(II) N-heterocyclic carbene complexes as organometallics interacting with thiol and selenol containing biomolecules. Dalton Trans, 42, 1657-66.

Ozdemir I, Temelli N, Gunal S, et al (2010). Gold(I) complexes of N-heterocyclic carbene ligands containing benzimidazole: synthesis and antimicrobial activity. Molecules, 15, 2203-10.

Pervaiz S, Clement MV (2002). A permissive apoptotic environment: function of a decrease in intracellular superoxide anion and cytosolic acidification. Biochem
Biophys Res Commun, 290, 1145-50.

Rubbiani R, Can S, Kitanovic I, et al (2011). Comparative in vitro evaluation of n-heterocyclic carbene Gold(I) complexes of the benzimidazolylidene type. J Med Chem, 54, 8646-57.

Selim ME, Hendi AA (2012). Gold nanoparticles induce apoptosis in MCF-7 human breast cancer cells. Asian Pac J Cancer Prev, 13, 1617-20.

Tedesco S, Doyle H, Blasco J, et al (2010). Oxidative stress and toxicity of gold nanoparticles in Mytilus edulis. Aquatic Toxicology, 100, 178-86.

Teyssot ML, Jarrousse AS, Manin M, et al (2009). Metal-NHC complexes: a survey of anti-cancer properties. Dalton Transactions, 6894-902.

Vasudevan KV, Butorac RR, Abernethy CD, et al (2010). Synthesis and coordination compounds of a bis(imino) acenaphthene (BIAN)-supported N-heterocyclic carbene. Dalton Transactions, 39, 7401-8.

Weskamp T, Kohl FJ, Hieringer W, et al (1999). Highly active ruthenium catalysts for olefin metathesis: the synergy of n-heterocyclic carbenes and coordinatively labile ligands. Angew Chem Int Ed Engl, 38, 2416-9. 